\title{
Arabic Back Channel Signals
}

\author{
Mohammad Anani \\ Department of English, Petra University \\ PO. Box 852366, Amman, Jordan
}

Tel: 962-6581-4059Ｅ-mail: manani@uop.edu.jo

Received: December 23, 2012 Accepted: January 14, 2012 Published: February 28, 2013

doi:10.5296/ijl.v5i1.2943 URL: http://dx.doi.org/10.5296/ijl.v5i1.2943

\begin{abstract}
Backchannel signals in Arabic conversational exchanges are unaccounted for either in form or in function. The primary objective of this research is therefore to describe the structure and function of those naturally occurring uttered phrases used in conversational exchanges for expressing approval or active engagement in the interaction. To achieve this purpose a corpus consisting of spontaneous conversational exchanges were recorded. The recordings were meant to represent typical family settings in which interaction usually takes place between close relatives or friends: males or females. The conversations were classified into types which represent conversational exchanges between women and men, and children. Reference is made to difficulties experienced by Arab learners of English when talking to Englishspeaking interlocutors, as a result of the differences in backchannel signals.
\end{abstract}

Keywords: Backchannel signals, Arabic, Frequency function 


\section{Introduction}

Backchannel signals in Arabic conversational exchanges are unaccounted for either in form or in function. The primary objective of this research is therefore to describe occurrence, structure and function of those naturally occurring uttered phrases used in conversational exchanges for expressing approval or active engagement in the interaction. Unlike English, backchannel words or phrases that provide 'feedback' to the speaker and their concomitant effect on how the information is presented is not very well-known to Arab interlocutors. Less well known is how backchannel behavior helps facilitate turn-taking, and keeps the conversation to go 'on track' by drawing attention to, and understanding of, what the speaker is saying.

Wales (2001) defines 'feedback' as "the process whereby a receiver's reactions to a message are picked up by the sender and monitored, so that adjustments can be made if necessary"(ibid: 147). Coulthard, M. (1992) maintains that backchannels are used to acknowledge, accept, or endorse information stated by the interlocutor. Yule (1998) stresses the point that backchannels are "vocal indications of attention" (ibid: 127).

Goffman (1976) maintained that backchannel signals are words or short utterances that provide feed back to the dominant interlocutor by indicating that the other participant in the conversation is still engaged in the conversation.

There seems a consensus of opinion among researchers in the field of spoken discourse that backchannels are devices used by an interlocutor to acknowledge or encourage participants in a conversation to continue talking (cf. Stenstrom, 1994:5). The English little words such as m, $\mathrm{mhm}$, yes, yeah signal active engagement in a conversational exchange; they are indicative of message reception and acceptance.

Arabic backchannel signals, as features typical of spoken interaction, have not yet been investigated. The primary purpose of this study is therefore to explore what backchannels are used in typical Arabic conversational exchanges.

\section{Objectives}

(i) to identify words and or lexical phrases or stereotyped utterances which are used to encourage the speaker to continue talking

(ii) to explore the various forms, functions and gender impact if any, on the selection of backchannels.

(iv) to show the frequency of backchannels in Arabic conversational exchange

\section{The Corpus}

The corpus of this study consists of conversations between dyads of two speakers each. The conversations were labeled 'female-female' (F1 -F2, F-3--F-4, male-male, M5-M6), and adult-child (A7-C8) and child-child (C9-C10). The recordings produced for each conversation were of good quality. They were conducted in natural settings between close friends or family members. 


\section{Procedure}

There are basically two kinds of free utterances with which backchannels are closely linked; they are distinguished by position of utterance i.e. whether it is first utterance on a new theme or whether it is second utterance on a theme already given or introduced. The first type is called 'stimulus' ( $\mathrm{St}$ ) and the second type is called 'response'(R). In Jordanian spoken Arabic, back channels which serve to raise the degree of interest for further conversation may be identified on formal, positional and semantic grounds. Formally, they are morphologically simple free forms which could occur independently. Unlike other Arabic open word classes whose roots are subject to morphological processes of derivation by infixation and/or suffixation, backchannel words are invariable; they cannot undergo any of the morphological processes which members of other word classes can. For example; backchannel words such as /?a:/ aah 'Okay', /Tajjib/ 'all right/ cannot undergo nominal formations with the nominal suffixes -uun, -aat. (In this context, one needs to point out that the words 'Taybeen, Tayba:t, ?aahaat' occurring elsewhere belong to a different lexical entry and have nothing to do with the backchannel words under discussion). Similar to other invariable words in the language, backchannel words seem to have little 'meaning' in themselves and constitute a closed class in that the number of items in this class is finite and the items are related in such a way that alterations or replacement by other members are not possible.

Positionally, the identification of backchannel items is best achieved by considering the structurally meaningful places which they typically occupy in 'response' sentences. A backchannel item typically occurs initially in response to a 'stimulus'. Semantically, backchannel words show greater interest and a positive reaction to what is being said.

Within the framework described above, it is possible to recognize three classes of backchannel words/ phrases:

(i) Vocalizations such as (uh-huh, mhm, hmmmmm)

(ii) 'Continuers' which facilitate turn-taking and keeps the conversation 'on track' e.g. (?aa,eeh, 9an 3add,)

(iii) 'Intensifiers' such as emphasizing words and lexical phrases used to express understanding, appreciation and to some extent admiration of what the speaker is saying. These items are closely linked structurally to a preceding utterance. e.g. 'bi3annin' 'fantastic', 9azi: $m$ 'great', ?akiid 'sure', bizzabT 'precisely', ja bayy ma (?alazzik)/'How nice you are'

The following tables display occurrence, percentage and function of back channel words in each text: 
Table 1. Arabic backchannels (F1-F2)

\begin{tabular}{|c|c|c|c|c|}
\hline Text Type & Item & Occurrence & percentage & Function \\
\hline \multicolumn{5}{|l|}{ F1-F2 } \\
\hline & ?a:h 'okey' & 33 & 19.4 & (agreeing) \\
\hline & $m h m$ & 25 & 14.7 & (encouraging) \\
\hline & $\begin{array}{l}\text { xalas ' that's } \\
\text { it' }\end{array}$ & 12 & 7.00 & $\begin{array}{ll}\text { (turn } & \text { /topic } \\
\text { shifting) } & \\
\end{array}$ \\
\hline & $T a b$ & 12 & 7.00 & $\begin{array}{ll}\text { ( partly } \\
\text { disagreeing) }\end{array}$ \\
\hline & $\mathrm{SaH}$ 'all right & 11 & 6.30 & (eliciting) \\
\hline & $\begin{array}{l}\text { 9anjadd } \\
\text { 'really?' }\end{array}$ & 10 & 5.8 & (showing interest) \\
\hline & Tayyib'okey' & 10 & 5.8 & (complying) \\
\hline & balla? 'really' & 10 & 5.8 & (encouraging) \\
\hline & yaxti ma... & 8 & 4.7 & (sympathizing) \\
\hline & ?aywa & 6 & 3.5 & (agreeing) \\
\hline & bizzabT & 6 & 3.5 & (confirming) \\
\hline & hmmmm & 6 & 3.5 & ( encouraging) \\
\hline & yalla' go on' & 6 & 3.5 & (pleading) \\
\hline & bas? 'but' & 5 & 2.9 & (partly disagreeing) \\
\hline & Tab9an & 4 & 2.3 & (emphasizing) \\
\hline & $\begin{array}{l}\text { 9afikra on } 2^{\text {nd }} \\
\text { thought }\end{array}$ & 2 & 2.3 & (transitioning) \\
\hline & $\begin{array}{l}\text { mbala'that's } \\
\text { right' }\end{array}$ & 2 & 1.1 & (reassuring) \\
\hline & $\begin{array}{l}\text { ?akiid } \\
\text { 'certainly' }\end{array}$ & 1 & 0.5 & (emphasizing) \\
\hline & $\begin{array}{l}\text { ' walla } \\
\text { 'really' }\end{array}$ & 1 & 0.5 & $\begin{array}{l}\text { (pleading, } \\
\text { emphasizing) }\end{array}$ \\
\hline & maaši & 1 & 0.5 & $\begin{array}{ll}\text { (complacent and } \\
\text { agreeing) }\end{array}$ \\
\hline & & ----- & ----- & \\
\hline & & 170 & $100 \%$ & \\
\hline
\end{tabular}

Table 1 lists the number and percentage of occurrence of backchannels in 'response' sentences. 
Table 2. Arabic back channels (F3 - F4)

\begin{tabular}{|l|l|c|c|l|}
\hline Text Type & item & occurrence & percentage & function \\
\hline F3 - F-4 & & & & \\
\hline & ?a:h & 20 & 33.3 & (agreeing) \\
\hline & ?ywa & 15 & 25.0 & (agreeing) \\
\hline & Tayyib & 7 & 11.6 & (complying) \\
\hline & yalla & 6 & 10.0 & (pleading) \\
\hline & 9an 3 add & 3 & 5.0 & (showing interest) \\
\hline & bas & 2 & 3.3 & (partly disagreeing \\
\hline & balla & 2 & 3.3 & (encouraging) \\
\hline & 9afikra & 2 & 3.3 & (transitioning) \\
\hline & walla & 2 & 3.3 & (pleading, \\
& & & & emphasizing) \\
\hline & xalaS & 1 & 1.6 & (turn /topic shifting) \\
\hline & & ------- & ---- & \\
\hline & Total & 60 & $100 \%$ & \\
\hline & & &
\end{tabular}

Table 2 shows the number of occurrence of Arabic backchannels

In Text 2 (conversational exchange between female and female)

Table 3. Arabic back channels M5-M6

\begin{tabular}{|c|c|c|c|c|}
\hline Text Type & item & occurrence & percentage & function \\
\hline \multicolumn{5}{|l|}{ M5 - M6 } \\
\hline & ?a:h 'okey' & 14 & 21.2 & (agreeing) \\
\hline & Tayyib 'okey' & 13 & 19.6 & (complying) \\
\hline & $\begin{array}{l}\text { ya9ni } \\
\text { 'mean..' }\end{array}$ & 10 & 15.15 & (restarting) \\
\hline & ?aywa 'all ight' & 8 & 12.12 & (agreeing) \\
\hline & bas 'enough' & 7 & 10.6 & (partly disagreeing) \\
\hline & maaŠi 'all right' & 6 & 9.9 & $\begin{array}{l}\text { (complacent and } \\
\text { agreeing) }\end{array}$ \\
\hline & xalas & 4 & 6.06 & (turn /topic shifting) \\
\hline & ya salaam & 2 & 3.03 & (emphasizing) \\
\hline & walak 'you' & 1 & 1.5 & $\begin{array}{l}\text { (reproaching } \\
\text { critically) }\end{array}$ \\
\hline & (walla) mumta:z & 1 & 1.5 & (appreciating) \\
\hline & total & ----- & ------ & \\
\hline & & 66 & $100 \%$ & \\
\hline
\end{tabular}


Table 3 displays back channels in terms of frequency and function between adult males

Table 4. Arabic back channels (A7-C8)

\begin{tabular}{|l|l|l|l|l|}
\hline Text Type & item & occurrence & percentage & function \\
\hline A7-C8 & & & & \\
\hline & $? a:(: h)$ & 18 & 30.0 & (agreeing) \\
\hline & $m h m$ & 10 & 16.6 & (encouraging) \\
\hline & ya9ni & 6 & 10 & (restarting) \\
\hline & Tayyib & 5 & 8.3 & (complying) \\
\hline & Tab & 4 & & \\
\hline & $\begin{array}{l}\text { Partly } \\
\text { disagreeing }\end{array}$ & 6.6 & & \\
\hline
\end{tabular}

Table 4 shows back channels occurring in instance of adult-child conversation.

Table 5. Arabic back channel C9-C 10

\begin{tabular}{|l|l|l|l|l|}
\hline C9-C10 & item & occurrence & percentage & function \\
\hline & $? a:$ & 24 & 54.5 & (agreeing \\
\hline & Tab & 8 & 18.8 & $\begin{array}{l}\text { (partly } \\
\text { disagreeing) }\end{array}$ \\
\hline & $9 a n 3 a d d$ & 2 & 4.5 & $\begin{array}{l}\text { (showing } \\
\text { interest) }\end{array}$ \\
\hline & Tajjib & 6 & 13.6 & (complying) \\
\hline & $? e:(h)$ & 4 & 9 & (agreeing \\
\hline & Total & 44 & $100 \%$ & \\
\hline
\end{tabular}

Table 5 shows frequency of backchannels in a conversational exchange between child and child

\section{Discussion}

In everyday conversation, speech contains words and lexical formulae which serve the sole purpose of maintaining social friendly relationships. There exist in Arabic a number of forms whose function is to indicate to the speaker that the listener is still engaged in the conversation. They typically function as (i) 'continuers' i.e. encouraging further conversation (ii) ' one-word emphasizing 'i.e. serving to indicate understanding of a previous talk and (iii) 'utterance -emphasizing, i.e. serving to intensify the degree of attention called to the utterance as a whole.

In terms of the relative frequency of occurrence, the following list of backchannel words crop up as the most frequent in conversational exchanges. 
5.1 Backchannel words: /?a:/

- /?ㅁ:ㅁa

It is the most frequent backchannel; it occupies top position in all the percentages calculated for all conversations. The English translation equivalent to /? $\underline{\mathbf{a}}$ :/ is 'okay' , 'yes' .

Examples:

FI - F2

A. win3iib B.M., ?usukti 'well get B.M., calm down.

B. /? $\underline{\text { a: } / ~ ' o k a y ' ~}$

A. ba9atlik ?i: me:l fi: 55 Su:ra li?a:xir ?anwa:9 il B.M bi?alwa:nha, bi?anw:9ha u min 3uwwa u min barra u min /udda:m u min wara. 'I've sent you an email containing the latest B M models: color and look from the inside, outside, front, side and back.'

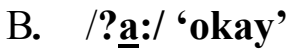

A. BM silver

B. /?a: ?ㅁa:/ 9riftha 'okay okay' 'I knew'

/?a:/ sometimes serves as a direct response to a question; it is interdependent with its related stimulus sentence. e.g.

\section{C9-C10}

A. fii 9inab 9inna? 'Havelwe got grapes?'

B. /?a: / 'yes'

A. ?intu ilyoom 9aTTaltu? 'Are you on holiday today?'

B. /?ㅁa:/, /?ㅁa:/

5.2 Backchannel words: Tayyib

\section{Tayyib}

The word / Tayyib/ is very frequent at the beginning of a turn. In contrast with /? $\underline{\text { a: }}$ / it does not act as a direct response to a question, e.g.,

\section{M4 - M5}

\section{A. ha:t la ̌̌uuf. 'Let me see'}

Tayyib int fa:him kul ha:da illi katabtu? 'okey, Did you see what you've written?

B. /?a:/ 'yes'

\section{A. /Tayyib?, /Tayyib/ mumta:z. 'okay, okay, super'}

/Tayyib/ sometimes acts as a direct response to a command, e.g. 


\section{Macrothink}

\section{M4 - M5}
A. Tayyib yalla ru:H u ta9a:l bsur9a.'okey Go and comeback quickly'
B. Tayyib 'okay'

A. ?isma9 , d3iib ma9ak ilqaamuus. 'listen, bring with you the dictionary.'

B Tayyib 'okay'

\subsection{Backchannel words: ?aywa}

\section{?aywa}

The word-form? aywa (or its dialectal variant) /? e:/ 'yeah' signals agreement acting as a direct response to a question, e.g.,

\section{A 7 - C8}
A. kunt bilbeet imba:riH? 'Were you at home yesterday?'
B. ?aywa 'Yeah'
A. inte bti9rif til9ab ŠaTaran3? 'Do you know how to play chess'
B. ?aywa. 'Yeah'

When ?aywa occurs at the beginning of a turn or within a larger turn it signals great interest in what someone is saying and expresses greater encouragement for further information e.g.,

\section{F1 -F2}

A. btista9imli illaqab nafsu fi 3 amii 9 qanawaat idardaŠe? 'Do you use the same nickname in all chat channels?/

\section{B ?aywa}

\section{A. lee ̌̌?'Why?'}

B li?annu il?ism ?aw illaqab illi baxtaaru ....
A. aha

B ?aywa 'Yeah'
A. bikuun 'will be.'
B. ?aywa 'Yeah'
A. bikuun 'will be...
B. ?aywa, ?aywa.'yeah.

A. ?aHabb u ?afDal ?isism bi9abbir 9an ŠaxSiyti ' the best and the most favorite name which reflects my personality' 


\section{Macrothink}

?aywa can also be used to indicate a positive attitude or reaction, confirmation or

Acceptability of what the other interlocutor is doing, e.g

F4 - F6

A. min nuqTit ilbidaaya aSSaHiiHa/ ?aywaa? 'right from the start, yeah?

B. ?aywa intabahti? 'Have you noticed that',

A. ?aywa heek mumtaaze' just like that, yeah very good',

B. ?aywa maa tsiibi ?iidik. 'Yeah, don't leave your hand'

B. ?aywa heek 'okay just like that/

5.4 Backchannel words: Hmmm

\section{Hmmm}

Backchannel cues include vocalizations $\mathrm{m}-\mathrm{m}-\mathrm{mhm}$, hmmmm which indicate agreement with what the speaker has said; they express willingness for more active engagement in a conversational exchange e.g.

\section{A-7-C8}
A. bitHibbi il? aGaani int? 'Do you like songs?'
B. $\boldsymbol{m m m m}$
A. ?eeŠ hai iSSuura? 'What's this picture of?
B maa ba9rif 'I don't know..'

A. $u$ hai?

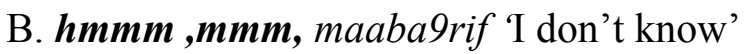

A. Tab ya9ni ?a3iiblak ma3alle? 'Shall I get you a drawing magazine?'

B. hmmm, //arsum 9aleeha/ 'to draw on it?

The types of speech acts with which $\mathbf{h m m}$ m are linked are 'Directives' i.e attempts to get the hearer to do something as shown above.

\section{F1-F2}
A. d3ibt twiids zeiti I bought an olive tweeds'
B. uhuh

A. $u$ d3ibt 3akeet karmiidi Tawiil., 'and I bought a long karmiidi 3aket, u 3ibt banTaloon zeiti loo west ' and a low west olive trousers.'

B. uhuh 


\section{Macrothink}

International Journal of Linguistics

ISSN 1948-5425

2013, Vol. 5, No. 1

A. Šu illaqab 'nickname' illi btistaxidmiih? 'What nickname do you use (when chatting)

b. laqlaq

A. uhuh

B winti?

A. lady 85

B. uhuh

\subsection{Backchannel words: $\mathrm{SaHH}$}

- $\mathbf{S a H H}$ 'yes, that's right'

In a conversation, it is important to let the person know if what he is saying is satisfactory or to the point. The word $\mathrm{SaHH}$ is used by the speaker as a discourse tag with the following functions;

(i) It enables the speaker to carry the conversation further by eliciting a response from the hearer, where a tagless declarative (without $\mathrm{SaHH}$ ) would not achieve this end e.g.

\section{F3-F4}

A. bidna mudarris qadiir qaadir 9ala ?idaarit ISSaff, $\mathbf{S a H H}$.

A. 'We want a qualified teacher to control the class, don't we?'

B. $\mathbf{S a H H}, \mathbf{S a H H}, \mathbf{S a H H}$ 'That's right, that's right'

(ii) It is used to reinforce the belief that the listener has the same opinion or feeling as the speaker e.g

A. ?akiid inti bitHibbi ilmansaf, $\mathbf{S a H H ?}$ 'You love mansaf, don't you'

B. SaH, $\mathbf{S a H H}$.'true', 'that's right'

(iii) $\mathbf{S a H H}$ can also be used to show reaction to something that someone has just said, e.g to show interest, surprise, or anger, e.g.

A. inti lbisti iTTa?m issakani il?aSiir, SaHH. 'You've put on the grey suit, don't you? $u$ ruHti fii 9al3aam9a, SaHH, SaHH? 'You've gone to the university wearing it, haven't you?'

B. $\mathrm{SaHH}, \mathrm{SaHH}$. 'right'

5.6 Backchannel words: 9an 3add

- 9an 3add

Backchannel 9an 3add is very common in women's speech. It is used to facilitate turn-taking and to maintain continuous flow of conversation e.g.

F3 -F4 


\section{Macrothink}

International Journal of Linguistics

ISSN 1948-5425

2013, Vol. 5, No. 1

A. maa ?ultiili Šu ra?yik filmag taa9i? 'You didn't tell me what you think of my mug?

B. humme tneen hilwiin 'both mugs are gorgeous'
A. 9an 3add 'really'
B. ?akiid 'definitely'

A. $t$ Gaddiini? ' could you give me a meal for lunch?

B ?aa, Tab9an Habibti. 'of course, love'
A. 9an zadd?'really?
B.walla 9an 3add 'honestly', bamzaHŠ 'I'm not kidding'

A. ?isma9i hai hai limTaffaye ya9ni Zahra blaban hai raH taakli? aSaab9ik waraaha.

Listen, this mTaffaye, you know, Zahra and yogurt will make you 'eat your fingers, too'

B. ?akiid? 'really?'

A. laa, 9an3add, bamzaHŠ. 'honestly, I'm not kidding'

B. uh-uh

A. inti bas taakliiha HayuGma 9aleeki' just when you eat it, you'll be carried away'

B. yuGma 9alayy 'carried away....?'

A. 9an 3ad 'honestly, I eat it, for breakfast, lunch and dinner'

B walla 'by God'

A. bi33nnin, ya(ni baHkiilik b33annin' I'm telling you, it's fabulous, fabulous.

5.7 Backchannel words: balla

- balla

balla is used with a rising intonation when the listener is actively engaged in the conversation and at the same time is showing interest for further information, e.g.

\section{F3-F4}

A. xallaSti imtiHanaatik? 'Have you finished your exams?

B. laa walla bukra ?awwal yoom. 'Not really, no, tomorrow is the first day.

A. balla ?'Are you sure?

B. ?a: walla, ?ili min yoom ilxamiis madwuuŠ muxxi. "Yes, I'm. My mind has been dizzy since Thursday.,"

A. ?a: bi9iin alla 'God may help you' 


\section{Macrothink}

A. bti9irfi ilwaaHad heek bti33amma9 9aleeh ?aŠyaa? 'you know, things pile up'

A. /?a:, ?a:, ?a:/walla. 'Yes, indeed'.

A. alla y3iib illi fii ilxeer 'May God give us his blessing for our good deeds.'

A. inŠaalla. ' I hope so'

B. in ̌́aalla . 'I hope so'

5.8 Backchannel words: walla

- walla

walla is uttered to draw the speaker's attention. It has a simultaneous dual function: one-word emphasizing and the other utterance-emphasizing, i.e. serving to intensify the degree of attention to the utterance as a whole e.g.

A. Šu biddik tuTubxi 9alGada?' What're you going to cook for lunch '

B. xaaTri ?aTbux mansaf, kulhum biHibbuu. 'I would like to cook mansaf.'They all love it'

A. walla ma ?a9adna. ?u9di iŠrabi Šai. 'We haven't been able to relax'Have some tea?

B. walla maa 9indi wa??akiidt. walla maa biSaHli . biddi ?aruuH a3iib liwlaad min ilmadrase(h). 'I really don't have time. 'I really can't manage'

A. walla daayman mista9i3le lamma bitzuriina 'You're always in a hurry when you visit us.'

B. walla mistaa9i3le. biddi ?alHaq a3iib liwlaad min ilmadrase

A. ?alla ma9aaki. Salmi 9aleehum kulhum. 'God be with you. Say salaam 'Hello'to all of them'.

B. ?alla ysalmik. 'God be with you'.

5.9 Backchannel words: ?akiid

\section{- ?akiid}

The backchannel word ?akiid is uttered by the listener to give greater support and reinforcement to what the speaker is saying. In addition to being a word-emphasizing i.e. the lexical meaning of the word is 'certainly, sure', it is also utterance-emphasizing in the sense that the speaker is willing to give his support and encouragement to the on-going 'topic' of discourse, e.g.

A. ya ?alla ?addee ̌̌ miŠtaa? lik ya ?immi. ?alla ma ?aHla riiHit Tabiixik’.walla

bi3annin. 'How great I, m looking forward to seeing you. How marvelous the smell of your cooking is. It's fabulous'.

B. haada min zoo?ik. Tabaxtlik illi bitHibbii, ?inti wiliwlaad. 'Thank you. I've cooked what you favour most' 
A. ?akiid mansaf. 'sure, 'mansaf'

B. ?akiid.

5.10 Backchannel words: XalaS

- XalaS

XalaS is a backchannel closing signal used by the interlocutors to end talking about a topic e.g.

\section{F1- F2}

A. Tab XalaS, XalaS. 'That's enough, enough.'

B. Ya bayy ilyoom ktiir Hakiina. 'We've talked too much today.'

A. ? usukti XalaS. 'Be quiet, enough'.

B. Zhi?it 'I'm fed up'.

A. Tayyib ruuHi. 'OK. Go'

B. XalaS z9ilt maa biddi ?aHki.' enough, I'm cross, I don't want to talk'

5.11 Backchannel words: nbala

\section{- nbala}

nbala is restricted in use. It initiates a response to a negative statement when the speaker wants to check if it is true; the listener rejects or denies the the negative assumption e.g.

\section{$\mathrm{A}-7-\mathrm{C} 8$}

A. ?aSlan ?inte muи ŠaaTir? 'You're not cute, are you?

B. nbala 'Yes, I am.'

A. ?inte maa bti9rif tursum. 'You don't know how to draw, do you?'

B. nbala' 'Yes, I do'.

\section{Results and Conclusion}

Jordanian Arabic conversational exchanges vary according to group, topic and role-relationships among interlocutors. Yet, common to all conversational exchanges is a closed list of backchannel signals which have a key effect on the flow of speech. They exercise influence on the development of the thematic structure of conversation as participants' transition from one topic to another. The most common backchannel signals occurring in natural conversational exchanges between female-female, male-male, adult-child and child-child have been described and the function of each has been elucidated. The backchannel list includes the following signals;?aa, ?aywa, Tayyib, Tab, hmmm, mmm, uh-uh, balla, walla, ?akiid, SaH, 9an 3add, nbala, bizzabT. These words are used to convey meaning related to agreement, encouragement, and reinforcement to conversational 
turn-taking behavior. They have a crucial role in keeping the conversation 'on track' Use and frequency of these signals in conversational exchanges is culture-specific. The data shows a higher frequency of occurrence of vocalizations $h \mathrm{mmm}, \mathrm{mmm}$ and the backchannel signal l? a:/ in adult-child and child-child conversational exchanges. There is a tendency for women to use more emphasizing backchannel words and phrases than men Backchannels such as 9an 3add. ya bajj ma ....and yee /ji:/ are of higher frequency in women's than in men's speech. The following table displays the relative frequency of backchannel signals distributed according conversational exchange type:

Table 6. Back channels distributed according to text type

\begin{tabular}{|l|l|l|l|l|l|l|}
\hline Signal & F1-F2 & F3-F4 & M5-M6 & A7-C8 & C9-C10 & Signal Type \\
\hline ?a: & 19.4 & 33.3 & 21.2 & 30 & 54.5 & continuer \\
\hline mhm & 3.5 & & & 16.6 & & vocalization \\
\hline uh-huh & 14.7 & & & & & vocalization \\
\hline Tayyib & 5.8 & 11.6 & 19.6 & 8.3 & 13.6 & continuer \\
\hline ?aywa & 3.5 & 25 & 12.2 & & & continuer \\
\hline SaH & 6.30 & & & & 4.5 & continuer \\
\hline 9an 3ad & 5.8 & 5 & & & & continuer \\
\hline balla & 5.8 & 3.3 & & & & continuer \\
\hline mbala & 1.1 & & & & & continuer \\
\hline maaši & 0.5 & & 9.9 & & & continuer \\
\hline xalas & & 1.6 & 6.0 & & & closing \\
\hline ?akiid & 0.5 & & & & & intensifier \\
\hline walla & 0.5 & 3.3 & 1.5 & & & intensifier \\
\hline bizzabT & 3.5 & & & & & \\
\hline Tab9an & 2.3 & & & & & intensifier \\
\hline yalla & 3.5 & 10.0 & & & & \\
\hline
\end{tabular}

The table shows that?aah and Tayyib are the most frequently used back channels. Clearly, they crop up as frequent devices used in conversational exchanges. The highest percentage of their use is in the text $\mathrm{C} 9-\mathrm{C} 10$ followed by A7-C8 in which children are involved in the exchange.

The items ballah and 9an 3add could be considered gender-specific because they are used frequently in the text types (F1-F2) and (F3-F4).

\section{Pedagogic Implications}

An important aspect of an English conversational exchange is how participants respond to given stimuli. It is important to let an interlocutor know whether what he is saying is to the point(cf Mitchell, et al 1989: 66 ). A participant is expected to respond to other participants' ideas and to express both agreement and disagreement. In both languages Arabic and English agreeing is easy. It is enough to say 'yes', or even simply to nod. However; beyond that, the devices and strategies adopted for emphasizing agreement or disagreement are quite different. 


\section{Macrothink}

In English emphasis is realized in various ways: by accentuation, i.e. the tonic syllable placement in words and of the nucleus in sentences, by the use of the emphatic 'operator' $d o$, and by emphasizing adjuncts (cf Mitchell op. cit: 65).

Arab interlocutors focus on certain stereotyped lexical words and phrases, e.g. walla , ?akiid, bizzabT, SaH. Arab learners of English therefore experience difficulty in responding to tagged questions and find it difficult to follow the focusing process adopted by the English speaking participants. As a result, the overall performance is adversely affected and mutual intelligibility is impeded. Whereas response to an English tagged question requires knowledge of polarity according to which either a negative tag follows a positive main clause and vice versa, or the tag has the same polarity as the main clause, Arabic thematic structure lacks equivalent polarity. Arab learners of English therefore experience difficulty in giving an appropriate response to tagged questions such as:

(i) St. positive- $\mathbf{R}$ operator + pronoun only:

\section{English St.}

I'm very keen on pop music. So am I.

I don't like students smoking. Neither do I.

\section{Expected Arabic Response}

u? ana kamaan 'me too' u ?ana kamaan' me too'

(ii) St. negative - tag negative:

\section{English St \\ R.(disagreeing) \\ Expected Arabic Response}

I can't stand horror films Oh, can't you?

I really don't like musicals. Oh, don't you? me too ' $u$ ? ana kamaan'

me too ' $u$ ?ana kamaan

(iii) St. positive - tag positive

\section{English St. $\quad$ R. (disagreeing) Expected Arabic Response}

I really like Osman's songs. Oh, do you?

I'm rather keen on swimming. Oh, are you? '?akiid? '9an 3add? 'really?

'balla, SaHiiH? 'Is that true?'

(iv) $R$ with an additioning tag:

\section{English St \\ R. (agreeing)}

Isn't it sad about Sabriya. Yes, it's terrible ,

What a good thing her isn't it?

Husband wasn't there

The trouble with Sami

is that he's always

borrowing money.

\section{Expected Arabic Response}

'?aa walla' It is indeed.' 


\section{Macrothink}

International Journal of Linguistics

ISSN 1948-5425

2013, Vol. 5, No. 1

In a lively conversation involving English and Arab participants, the backchannels used by Arab interlocutors are expected to be expressed in ways that are appropriate to the

Arabic conversational setting, That is to say agreement or disagreement is signaled by the use of 'me too', 'really', or 'yes indeed'. Although the English participants in a given conversational exchange may depend on other visual cues to understand the 'gist of the message', the inappropriate response the 'unexpected' Arabic translation-equivalents of

Arabic response lexical signals can affect mutual intelligibility and meaningful performance.

\section{References}

Coulthard, M. (1992). Introduction to Discourse Analysis, $2^{\text {nd }}$ ed. : New York: Longman.

Duncan, S. (1973). 'Toward a Grammar for Dyadic Conversation', Semiotica 29-56.

Goffman, E. (1976). Replies and Responses: Forms of Talk. Oxford: Blackwell.

Hatch, E., \& Brown, C. (1995). Vocabulary, Semantics, and Language Education.

Hatch, Evelyn. (1992). Discourse and English Education. $1^{\text {st }}$ ed. Cambridge: Cambridge University Press.

Mitchell, T.F., \& El-Hassan, S. (1989). English Pronunciation for Arabic Speakers. Essex: Longman.

Orestrom, Bengt. (1983). Turn-Taking in English Conversation. $1^{\text {st }}$ ed. Lung: Gleerup.

Stenstrom, Anna-Brita. (1994). An Introduction to Spoken Interaction. $1^{\text {st }}$ ed. New York: Longman.

Thorne, B., \& N. Henley. (1975). Language and Sex: Differences and Dominance. Rowley Mass: Newbury House.

Wales, Katie. (2011). A Dictionary of Stylistics. $2^{\text {nd }}$ ed. Har;ow: Pearson Education Limited.

White, Ron. (1997). "Back channeling. Repair, Pausing, and Private Speech" Applied Linguistics, 18(3). http://dx.doi.org/10.1093/applin/18.3.314

Yule, George. (1998). Pragmatics. $1^{\text {st }}$ ed. Oxford: Oxford University Press. 